\begin{tabular}{|c|c|}
\hline 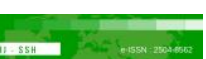 & Malaysian Journal of Social Sciences and Humanities (MJSSH) \\
\hline Malaysian Journal of & Volume 6, Issue 3, March 2021 \\
\hline (MJ-SSH) & e-ISSN : 2504-8562 \\
\hline & $\begin{array}{l}\text { Journal home page: } \\
\text { www.msocialsciences.com }\end{array}$ \\
\hline
\end{tabular}

\title{
Kecenderungan Berfikir Kritis dan Pencapaian Kesusasteraan Bahasa Inggeris Pelajar Tingkatan Empat Sekolah Menengah Daerah Kepala Batas, Pulau Pinang
}

\author{
Nur Adila Diyana Zulazmi ${ }^{1}$, Shahlan Surat ${ }^{1}$ \\ ${ }^{1}$ Fakulti Pendidikan, Universiti Kebangsaan Malaysia (UKM) \\ Correspondence: Nur Adila Diyana Zulazmi (p101142@siswa.ukm.edu.my)
}

\begin{abstract}
Abstrak
Kecenderungan berfikir kritis adalah satu aspek yang penting bagi melahirkan individu yang berkemahiran dalam pemikiran kritis. Kemahiran berfikir adalah salah satu aspirasi yang terkandung dalam Pelan Pembangunan Pendidikan Malaysia (PPPM2013-2025). Begitu juga dengan mata pelajaran Kesusasteraan Bahasa Inggeris, kecenderungan berfiikir kritis akan menggalakkan pelajar untuk meningkatkan cara berfikir yang berbeza. Oleh itu, kajian ini bertujuan untuk mengkaji tahap kecenderungan berfikir kritis di kalangan pelajar tingkatan empat. Di samping itu, kajian ini juga bertujuan untuk mengenal pasti hubungan kecenderungan berfikir kritis dan pencapaian Kesusasteraan Bahasa Inggeris pelajar tingkatan empat. Hasil daripada kajian ini dapat membantu para guru untuk meningkatkan pengetahuan mereka terhadap kecenderungan berfikir kritis. Seterusnya, reka bentuk kajian ini berbentuk kajian korelasi. Teknik persampelan rawak berstrata dan rawak sistematik telah digunakan untuk menentukan bilangan responden kajian. Seramai 310 orang pelajar sekolah menengah di daerah Kepala Batas, Pulau Pinang telah terlibat sebagai responden. Dapatan kajian menunjukkan tahap kecenderungan berfikir kritis berada di tahap tinggi dengan min skor 3.39. Tambahan pula, dapatan menunjukkan tidak terdapat perbezaan yang signifikan antara kecenderungan berfikir kritis terhadap pelajar lelaki dan pelajar perempuan tingakatan empat, $\mathrm{t}(310)=-0.130, \mathrm{p}>0.05$. Selain itu, dapatan kajian juga menunjukkan bahawa terdapat hubungan yang lemah $(\mathrm{r}=0.200, \mathrm{p}<0.05)$ antara kecenderungan berfikir kritis dan pencapaian mata pelajaran Kesusasteraan Bahasa Inggeris pelajar tingkatan empat. Ini menunjukkan apabila tahap kecenderungan berfikir kritis meningkat maka tahap pencapaian mata pelajaran Kesusasteraan Bahasa Inggeris juga meningkat. Oleh itu, implikasi kajian ini diharapkan dapat memberi pengetahuan yang baru kepada pihak Kementerian Pendidikan Malaysia, para pentadbir sekolah serta para guru untuk meningkatkan kecenderungan berfikir kritis dan pencapaian dikalangan pelajar.
\end{abstract}

Kata kunci: kecenderungan berfikir kritis, kemahiran berfikir, pencapaian pelajar, Kesusasteraan Bahasa Inggeris, sekolah menengah

\section{Critical Thinking Disposition and Students' Achievement in English Literature Subject Form Four Students at District Kepala Batas's Secondary School, Pulau Pinang}

Abstract 
Critical thinking disposition is an important aspect in producing individuals who are skilled in critical thinking. Thinking skills are one of the aspirations consists of the Malaysian Education Blueprint (20132025). Similarly, in English Literature subject, critical thinking disposition will encourage students to enhance their different ways of thinking. Therefore, this study aims to examine the level of critical thinking disposition for form four students. Furthermore, this study also aims to identify the relationship between critical thinking disposition and students' achievement in English Literature subject for form four students. Results of this study can help teachers to further improve their knowledge in critical thinking disposition. Next, a correlation study was used for this study. A stratified random sampling technique was used to determine the number of respondents who are involved in this study. A total number of 310 secondary students at Kepala Batas district, Penang were involved as respondents. The findings found that the level of critical thinking disposition is high with a mean score of 3.39. Furthermore, the findings show that there is no significant difference between critical thinking disposition towards male and female students of form four, $\mathrm{t}(310)=-0.130, \mathrm{p}>0.05$. The findings also showed a weak relationship $(\mathrm{r}=0.200, \mathrm{p}<0.05)$ between critical thinking disposition and students' achievement in English Literature subject for form four students. It indicates that when the level of critical thinking disposition increases, the level of achievement for English Literature subject also increases. Hence, implications of this study are expected to provide new knowledge to the Ministry of Education Malaysia, school administrators as well as teachers in enhancing critical thinking disposition and achievement among students.

Keywords: critical thinking disposition, critical thinking, student achievement, English Literature, secondary school

\section{Pengenalan}

Falsafah Pendidikan Kebangsaan (FPK) menerangkan bahawa pendidikan di Malaysia adalah suatu usaha yang bersinambungan ke arah memperkembangkan lagi potensi individu secara menyeluruh untuk melahirkan insan yang seimbang dari segi rohani, emosi, intelek dan jasmani berdasarkan kepercayaan dan kepatuhan kepada Tuhan (FPK 2020). Pelan Pembangunan Pendidikan 2013-2025 yang menjelaskan untuk terus mendukung hasrat FPK bagi memastikan bahawa pendidikan seimbang sebagai asas kepada aspirasi pelajar. Tambahan pula, kemahiran berfikir merupakan salah satu antara aspirasi pelajar yang dititikberatkan dalam Pelan Pembangunan Pendidikan 2013-2025. Siti Zahidah \& Abdull Sukor (2019) menyatakan kemahiran berfikir dikategorikan sebagai salah satu daripada faktor utama dalam sistem pendidikan sebagai usaha untuk menambah pertumbuhan daya akal pelajar

Kemahiran berfikir kritis adalah salah satu daripada komponen kemahiran berfikir. Kemahiran berfikir kritis juga terkandung dalam soalan-soalan yang berunsurkan amalan KBAT. Justeru, dalam merealisasikan usaha penerapan kemahiran berfikir kritis di kalangan pelajar, Kementerian Pelajaran Malaysia (KPM) telah memperkenalkan Kemahiran Berfikir Aras Tinggi, (KBAT) untuk menerapkan kemahiran berfikir di kalangan pelajar sekolah. KBAT telah menjadi elemen penting dalam perubahan kurikulum pendidikan yang dilakukan oleh pihak KPM dan diberikan pengutamaan semasa proses pembelajaran dan pengajaran berlaku di sekolah (Nurul Azmi, Nurzatulshima, et.al, 2017).

Namun, dalam merealisasikan KBAT di sekolah, terdapat beberapa masalah yang bakal dihadapi oleh pelajar apabila mereka tidak menguasai KBAT terutamanya di dalam sesi pembelajaran. Masalah utama yang dihadapi oleh pelajar ialah apabila kurangnya penerapan amalan KBAT, pelajar akan kurang berpengetahuan dalam mata pelajaran yang tertentu. Artha, Dewi dan Endang (2018) menjelaskan bahawa pelajar tidak dapat mencari elemen-elemen masalah dan menghubungkan masalah kerana kurang berpengetahuan di dalam mata pelajaran. Selain itu, pelajar tidak mampu untuk mengembangkan idea dalam penulisan disebabkan kurang berpengetahuan terhadap seseuatu topik yang berkaitan. Hal ini terjadi kerana pelajar tidak didedahkan dengan soalan-soalan yang berunsurkan KBAT (Syazana dan Zamri, 2018). Oleh itu, penerapan amalan KBAT perlu dititikberatkan di dalam sesi pembelajaran. 
Di samping itu, perkembangan KBAT akan membantu penglibatan guru dan pelajar dalam memberikan kerjasama terhadap penyelesaian masalah. Ini membuktikan bahawa apabila penerapan amalan KBAT berkurangan di kalangan pelajar, ia akan membantutkan penglibatan pelajar di dalam kelas. Norazlin Rusdin dan Siti Rahaimah Ali (2019) menerangkan bahawa pelajar tidak mampu mengeluarkan idea apabila guru menyediakan aktiviti yang berunsurkan KBAT. Tambahan pula, kurangnya penerapan amalan KBAT akan menyebabkan pelajar akan menghadapi masalah komunikasi bersama gurunya. Azieyana Aziz dan Christina Andi (2018) menerangkan bahawa guru tidak menggalakkan interaksi dua hala dalam soalan yang berunsurkan KBAT, malah guru hanya menggayakan proses hafalan dalam menerapkan kemahiran berfikir pelajar. Siti Fatimah, Nurul Ilyana dan Siti Nur Hidayah (2018) pula menjelaskan bahawa keputusan kajiannya mendapati bahawa komunikasi guru dan pelajar akan terbantut kerana pelajar hanya mendengar penjelesan daripada guru. Secara ringkasnya, penerapan amalan KBAT amat penting dalam kalangan pelajar kerana ia boleh membantu pelajar untuk meningkatkan pencapaian akademik di sekolah.

Oleh itu, dengan mengenalpasti tahap kecenderungan berfikir kritis dapat membantu pelajar untuk meningkatkan kefahaman soalan yang berunsurkan KBAT. Hal ini kerana, apabila pelajar menguasai kecenderungan berfikir kritis ia dapat membantu pelajar untuk menggunakan KBAT dalam menyelesaikan masalah dan mencari idea dalam soalan yang berunsurkan KBAT (Norazlinda dan Abdullah, 2017). Kajian ini juga dijalankan dalam mata pelajaran Kesusasteraan Bahasa Inggeris kerana mata pelajaran ini mengandungi soalan yang berunsurkan KBAT.

Oleh yang demikian, kajian ini dijalankan bagi mencapai dua objektif tersebut:

i. Mengenal pasti tahap kecenderungan berfikir kritis analitikal, berfikiran terbuka, mencari kebenaran, sistematik, keyakinan diri, ingin tahu dan kematangan pelajar tingkatan empat sekolah menengah daerah Kepala Batas, Pulau Pinang.

ii. Mengenal pasti perbezaan tahap kecenderungan berfikir kritis dalam kalangan pelajar tingkatan empat di sekolah menengah daerah Kepala Batas, Pulau Pinang berdasarkan jantina.

iii. Mengenal pasti hubungan antara kecenderungan berfikir kritis dan pencapaian Kesusasteraan Bahasa Inggeris pelajar tingkatan empat sekolah menengah daerah Kepala Batas, Pulau Pinang.

Selain itu, hasil penemuan kajian ini dapat menyumbang manfaat kepada pelbagai pihak terutamanya KPM, pentadbir sekolah, guru dan pelajar. Pihak KPM boleh meningkatkan dan mengemaskini rancangan mengajar guru dalam menerapkan kemahiran berfikir kritis. Kajian ini juga memberi manfaat kepada guru kerana guru boleh menerapkan amalan-amalan kemahiran berfikir secara kritis terutamanya dalam mata pelajaran Kesusateraan Bahasa Inggeris serta pelajar juga boleh menguasai soalan-soalan yang berunsurkan kemahiran berfikir secara kritis dengan lebih sempurna.

Artikel ini mengandungi empat bahagian. Pertama, artikel ini memerihalkan tentang tinjauan literatur yang berkaitan dengan kencenderungan berfikir kritis. Seterusnya, artikel ini akan membincangkan tentang metodologi kajian dan analisis data yang diperoleh melalui borang soal selidik. Kemudian, dapatan kajian akan dibincangkan dan dirumus. Akhir sekali, artikel ini akan membincangkan tentang perbincangan kajian, implikasi kajian dan cadangan kajian lanjutan berkenaan kecenderungan berfikir kritis yang boleh digunakan dalam kajian seterusnya.

\section{Sorotan Literatur}

Berdasarkan kajian-kajian lepas terdapat beberapa perbezaan yang sering berlaku dalam aspek kecenderungan berfikir kritis. Kajian-kajian yang telah dijalankan mendapati bahawa aspek-aspek kecenderungan berfikir kritis dikalangan pelajar berbeza-beza bergantung kepada situasi pelajar ketika berhadapan dengan kajian tersebut. Kani Ulger (2016) mendapati tahap analitikal dalam kecenderungan berfikir kritis mempunyai hubungan yang signifikan terhadap kemahiran berfikir kreatif. Dapatan kajian ini merumuskan bahawa tahap analitikal berada di tahap yang tinggi kerana tahap analatikal digunakan dalan penyelesaian masalah terhadap sesuatu perkara. Disamping itu, kajian Yorganci (2016) menjelaskan bahawa aspek analitikal dan aspek ingin tahu merupakan aspek yang tertinggi berbanding 
kelima aspek yang terdapat dalam kecenderungan berfikir kritis. Ini kerana, pelajar itu mempunyai kecenderungan dalam menaakul, menyoal dan meramal keadaan dalam pembelajaran. Pelajar juga mempunyai rasa ingin tahu dan keinginan intelektual untuk belajar di dalam kelas.

Selain itu, Liya (2016) menunjukkan bahawa aspek kencenderungan berfikir kritis yang mendapat markah tertinggi adalah dari aspek mencari kebenaran dan sistematik. Hal ini disebabkan, pelajar telah menunjukkan peningkatan yang ketara bagi aspek mencari kebenaran dan sistematik dalam model pembelajaran CBLL berbanding model pembelajaran biasa. Oleh itu, pengkaji merumuskan bahawa pembelajaran berbentuk model CBLL amat berguna dalam memupuk sikap pelajar terhadap kecenderungan berfikir kritis dan menghasilkan pelajar yang mempunyai kemahiran berfikir kritis yang tinggi dalam membuat keputusan.

Berdasarkan dapatan kajian yang dilaporkan oleh Jayanti, Harry, Redjeki dan Sriyati (2019) terdapat perbezaan dalam aspek kecenderungan berfikir kritis berlaku antara pelajar semester 1 dan semester 3 . Aspek kecenderungan berfikir kritis yang paling tinggi dikalangan pelajar pendidikan Biologi pada semester 3 ialah berfikiran terbuka dan analitikal. Manakala, bagi aspek kecenderungan berfikir kritis pelajar pendidikan Biologi semester 1 pula hanya aspek berfikiran terbuka mendapat skor min yang paling tinggi dikalangan mereka. Hal ini disebabkan, tahap pendidikan pelajar berbeza-beza. Pelajar semester 1 tidak mempunyai pengalaman yang banyak dari segi pengetahuan dan latihan. Selain itu, pelajar semester 1 juga memiliki rasa takut untuk bertanya, tidak berani mencuba perkara yang baharu dan tidak yakin terhadap keputusan yang dilakukan. Ini jelas terbukti bahawa pelajar semester 3 mempunyai kecenderungan berfikir kritis yang lebih tinggi berbanding pelajar dari semester 1 .

Pada waktu yang sama, perbezaan antara lelaki dan perempuan juga berkait rapat dengan kecenderungan berfikir kritis. Melalui kajian lepas yang dilaksanakan terdapat perbezaan pelajar lelaki dan perempuan dalam menguasai kecenderungan berfikir kritis. Hal ini berlaku disebabkan oleh lokasi sekolah. Kajian Dewi Iryani, Wahab dan Muhlis (2018) mendapati bahawa skor kecenderungan berfikir kritis pelajar lelaki adalah lebih tinggi daripada pelajar perempuan. Hal ini terjadi disebabkan faktor lokasi sekolah kerana pengkaji ini menyatakan bahawa pelajar yang berada di kawasan bandar memiliki kecenderungan berfikir kritis yang lebih tinggi daripada di kawasan luar bandar. Hal ini berbeza dengan kajian Selma (2019) di mana pengkaji ini menyatakan bahawa tidak terdapat perbezaan yang signifikan antara pelajar lelaki dan perempuan dalam kecenderungan berfikir kritis. Penemuan ini menunjukkan bahawa tahap dalam mata pelajaran Pendidikan Seni Visual pelajar perempuan tidak mempunyai perbezaan dengan pelajar lelaki dalam menggunakaon kemahiran berfikir kritis untuk menyelesaikan masalah. Jesteru, perbezaan jantina dalam kecenderungan berfikir kritis bagi pelajar lelaki dan pelajar perempuan bergantung kepada tahap kecenderungan berfikir kritis seseorang individu tersebut.

Pencapaian pelajar merupakan suatu aspek yang selari dengan kecenderungan berfikir kritis. Kajian Ghorbandordinejad dan Nourizade (2020) menerangkan bahawa kecenderungan berfikir kritis mempunyai hubungan yang positif dengan pencapaian. Kajian ini telah menggunakan kecerdasan emosi yang bertindak sebagai pengantara hubungan antara kecenderungan berfikir kritis dan pencapaian mata pelajaran Bahasa Inggeris. Kecerdasan emosi memainkan peranan yang penting dalam meningkatkan kecenderungan berfikir kritis dan pencapaian mata pelajaran Bahasa Inggeris. Hal ini kerana pelajar yang mempunyai kecerdasan emosi yang baik akan melahirkan pelajar yang aktif terutamanya di dalam bilik darjah dan mampu meningkatkan pencapaian mata pelajaran Bahasa Inggeris mereka.

Pada masa yang sama, kajian Salihuddin (2017) yang telah menjalankan kajian bagi mata pelajaran Fizik untuk mengkaji hubungan di antara kecenderungan berfikir kritis dan kreatif pelajar dengan pencapaian pelajar. Dengan menggunakan e-pembelajaran Kaedah Sokratik, pengkaji menjelaskan bahawa ia berkesan untuk meningkatkan tahap kecenderungan berfikir kritis dan kreatif serta pencapaian pelajar terutama tentang penyelesaian soalan yang berunsurkan KBAT dalam mata pelajaran Fizik. Di samping itu, kajian Robin dan Mark (2015) pula telah menjalankan kajian terhadap pelajar jurusan perniagaan. Berdasarkan hasil dapatan, pengkaji juga mendapati terdapat hubungan yang positif di antara kecenderungan berfikir kritis dan pencapaian pelajar dalam pembelajaran perniagaan. Selaras dengan itu, kecenderungan berfikir kritis yang paling menunjukkan hubungan positif dengan pencapaian adalah berfikiran terbuka. Hasil kajian ini menunjukkan bahawa pelajar yang menguasai berfikiran terbuka 
boleh bersetuju dengan pendapat dan pandangan orang lain. Pelajar juga mempunyai kelebihan yang lebih besar mengenai cara menyelesaikan kerumitan sesuatu masalah di dalam bilik darjah. Secara kesimpulan, apabila pelajar mula menguasai kecenderungan berfikir kritis pelajar akan mempunyai hubungan yang positif dengan pencapaian.

\section{Metod Kajian}

Reka bentuk kajian ialah kajian korelasi. Kaedah kajian berbentuk korelasi ini adalah bersesuaian dengan tujuan kajian ini untuk menentukan hubungan di antara dua pembolehubah iaitu kecenderungan berfikir kritis dan pencapaian Kesusasteraan Bahasa Inggeris pelajar tingkatan empat sekolah menengah daerah Kepala Batas, Pulau Pinang. Reka bentuk korelasi adalah reka bentuk bukan eksperimental di mana dua pembolehubah diukur melalui hubungan keduanya secara statistik (Myers et al, 2010). Populasi kajian terdiri daripada pelajar tingkatan empat yang berada di sekolah menengah di daerah Kepala Batas, Pulau Pinang. Jumlah keseluruhan populasi adalah sebanyak 1559 orang pelajar. Dalam mengenal pasti ukuran sampel, pengkaji telah menggunakan Krejcie dan Morgan (1970).

Selain itu, bagi menentukan jumlah sampel yang terlibat dalam kajian ini persampelan rawak berstrata telah digunakan di kalangan pelajar tingkatan empat di sekolah menengah daerah Kepala Batas, Pulau Pinang. Persampelan ini dilakukan kerana populasi kajian tidak seragam. Menurut Creswell (2005), teknik persampelan rawak berstarta adalah teknik yang digunakan kerana populasi tidak menunjukkan ketidakseimbangan ciri-ciri bagi suatu sampel. Prosedur persampelan ini dikira mengikut nisbah jumlah pelajar di sekolah tersebut iaitu seramai 1559 pelajar tingkatan empat terlibat di dalam kajian ini. Seramai $27(8.72 \%)$ pelajar dari SMK Bertam Indah, $32(10.20 \%)$ pelajar dari SMK Bertam Perdana, $33(10.80 \%)$ pelajar dari SMK Datuk Haji Ahmad Badawi, 33 (12.00\%) pelajar dari SMK Datuk Haji Abdul Kadir, 35 (11.22\%) pelajar dari SMK Dato' Kailan, 20 (6.54\%) pelajar dari SMK Gemilang, 24 (7.60\%) pelajar dari SMK Kepala Batas, 25 (8.00\%) pelajar dari SMK Haji Hassan Noh, 31 (10.10\%) pelajar dari SMK Pokok Sena dan 46 (14.82\%) pelajar dari SMK Sri Muda. Melalui prosedur ini juga seramai $150(48.4 \%)$ adalah pelajar lelaki dan $160(51.6 \%)$ adalah pelajar perempuan.

Seterusnya, bagi pemilihan pelajar yang terlibat di dalam kajian ini kaedah persampelan rawak sistematik telah digunakan. Kaedah ini dijalankan apabila pengkaji mendapat maklumat senarai nama pelajar tingkatan empat di setiap sekolah di daerah Kepala Batas, Pulau Pinang dari Pejabat Pendidikan Daerah Seberang Perai Utara (PPDSPU). Teknik rawak sistematik ini menggunakan formula mudah yang sistematik dengan memilih setiap individu dalam selang ke-n sehingga bilangan sampel yang dikehendaki tercapai (Mac Nealy, 1999). Setiap ahli ke-n dalam senarai nama pelajar tingkatan empat dipilih sebagai sampel di dalam kajian ini. Jumlah populasi kajian telah dikategorikan mengikut sekolahsekolah yang terlibat. Setiap responden ke-n membawa maksud responden yang dipilih untuk menyertai kajian ini. Selang persampelan ini diperoleh dengan membahagikan saiz populasi dengan saiz sampel.

Soal selidik telah diedarkan kepada 310 responden dengan menggunakan kaedah persampelan rawak berstrata dan rawak sistematik di kalangan pelajar tingkatan empat di sekolah menengah daerah Kepala Batas, Pulau Pinang. Kajian ini menggunakan borang soal selidik sebagai instrumen pengumpulan data. Untuk membina soal selidik yang baik, penyelidik merujuk kepada kajian penyelidikan lepas dan cuba memadankan soalan berdasarkan pemboleh ubah. Setiap item dalam bahagian ini diadaptasi oleh kajian Mei-Ling Yeh dengan Cronbach's alpha adalah 0.71. Oleh itu, borang soal selidik akan dibahagi kepada dua bahagian iaitu bahagian A dan bahagian B dan dengan jumlah keseluruhan 73 item.

Bahagian A mengandungi soalan berkaitan latar belakang demografi responden dan markah peperiksaan Bahasa Inggeris yang terkini. Item terdiri daripada skala nominal dan nisbah yang terdiri daripada jantina, kaum dan pencapaian peperiksaan Bahasa Inggeris yang terkini. Bahagian B mengandungi soalan berkaitan aspek kecenderungan berfikir kritis. 70 item akan diukur dengan menggunakan skala Likert untuk mengenal pasti tahap kecenderungan berfikir kritis di kalangan pelajar tingkatan empat di sekolah menengah daerah Kepala Batas, Pulau Pinang. Bagi setiap tahap ia mengandungi sembilan atau sepuluh soalan untuk dijawab oleh responden. Seterusnya, setiap item dalam bahagian ini akan dianalisis 
menggunakan skala Likert. Skala Likert tersebut terdiri daripada "Sangat tidak setuju" hingga "Sangat setuju". Bahagian ini akan bermula dari skor 1 yang merupakan skor terendah hingga skor tertinggi iaitu 5 untuk setiap item dalam tahap kecenderungan berfikir kritis.

\section{Hasil Kajian}

\section{Demografi}

Latar belakang 310 responden dijelaskan melalui jadual berdasarkan ciri demografi iaitu jantina dan kaum. Majoriti responden bagi kajian ini adalah pelajar perempuan di kalangan pelajar tingkatan empat iaitu seramai 160 responden $(51.6 \%)$ manakala selebihnya adalah 150 responden (48.4\%) iaitu pelajar lelaki. Manakala dari segi kaum, majoriti responden adalah terdiri daripada pelajar Melayu iaitu seramai 289 responden $(93.2 \%)$ diikuti oleh pelajar Cina dengan 14 responden (4.5\%) dan pelajar India dengan hanya 7 responden $(2.3 \%)$. Dapatan ini dianalisis berdasarkan kekerapan dan peratusan seperti yang dinyatakan dalam Jadual 1:

Jadual 1: Profil Demografi Responden Kajian

\begin{tabular}{lcc}
\hline Ciri-ciri demografi & Kekerapan $(\mathbf{N}=\mathbf{3 1 0})$ & Peratus \\
\hline Jantina & & \\
Lelaki & 150 & 48.4 \\
Perempuan & 160 & 51.6 \\
& & \\
Kaum & & \\
Melayu & 289 & 93.2 \\
Cina & 14 & 4.5 \\
India & 7 & 2.3 \\
\hline
\end{tabular}

Tahap Kecenderungan Berfikir Kritis Analitikal, Berfikiran Terbuka, Mencari Kebenaran, Sistematik, Keyakinan Diri, Ingin Tahu dan Kematangan di kalangan Pelajar Tingkatan Empat

Berdasarkan Jadual 2, min tertinggi bagi aspek kecenderungan berfikir kritis ialah aspek keyakinan diri iaitu $(\min =3.93)$ diikuti dengan aspek mencari kebenaran $(\min =3.49)$, aspek analitikal $(\min =3.44)$, aspek sistematik $(\min =3.40)$ dan aspek berfikiran terbuka iaitu $(\min =3.33)$. Disamping itu, aspek ingin tahu dan aspek kematangan mendapat min sederhana iaitu $(\min =3.09)$ dan $(\min =3.07)$. Seterusnya, tahap keseluruhan aspek kecenderungan berfikir kritis adalah 3.39 yang berada pada tahap tinggi. Oleh itu, dapatan ini menunjukkan bahawa tahap kecenderungan berfikir kritis mempunyai min yang berada di tahap tinggi di kalangan pelajar tingkatan empat.

Jadual 2: Analisis deskriptif tahap kecendeungan berfikir kritis

\begin{tabular}{lccc}
\hline \multicolumn{1}{c}{ Aspek Kecenderungan Berfikir Kritis } & Min & Sisihan Piawai & Tahap \\
\hline Analitikal & 3.44 & 0.85 & Tinggi \\
Berfikiran Terbuka & 3.33 & 0.82 & Tinggi \\
Mencari Kebenaran & 3.49 & 0.91 & Tinggi \\
Sistematik & 3.40 & 0.88 & Tinggi \\
Keyakinan Diri & 3.93 & 0.87 & Tinggi \\
Ingin Tahu & 3.09 & 0.74 & Sederhana \\
Kematangan & 3.07 & 0.98 & Sederhana \\
Min Keseluruhan & 3.39 & 0.86 & Tinggi \\
\hline
\end{tabular}




\section{Perbezaan Kecenderungan Berfikir Kritis Berdasarkan Jantina}

Ujian-t telah dijalankan untuk melihat perbezaan kecenderungan berfikir kritis berdasarkan jantina. Jadual 3 menunjukkan bahawa tidak terdapat perbezaan yang signifikan antara kecenderungan berfikir kritis terhadap pelajar lelaki dan pelajar perempuan tingakatan empat, $t(310)=-0.130, p>0.05$. Ini bermakna, pelajar lelaki dan pelajar perempuan mempunyai pengetahuan yang sama dalam kecenderungan berfikir kritis. Oleh hal yang demikian, hipotesis nol gagal ditolak. Justeru dapatan ini menunjukkan bahawa tidak terdapat perbezaan yang signifikan antara kecenderungan berfikir kritis terhadap pelajar lelaki dan perempuan tingkatan empat.

Jadual 3: Perbezaan kecenderungan berfikir kritis berdasarkan jantina

\begin{tabular}{lccccc}
\hline Jantina & $\mathbf{N}$ & Min & SP & T & $\begin{array}{l}\text { Sig (2- } \\
\text { tailed) }\end{array}$ \\
\hline Lelaki & 150 & 3.38 & .195 & & \\
Perempuan & 160 & 3.39 & .182 & & .896 \\
\hline
\end{tabular}

\section{Analisis Korelasi}

Ujian Korelasi Pearson telah digunakan untuk mengenal pasti hubungan antara kecenderungan berfikir kritis dan pencapaian akademik kesusasteraan bahasa inggeris pelajar tingkatan empat. Berdasarkan Jadual 4, terdapat hubungan yang signifikan antara akecenderungan berfikir kritis dan pencapaian Kesusasteraan Bahasa Inggeris pelajar tingkatan empat dengan nilai $r=0.200$, sig $=0.000, p<0.05$. Oleh itu, hipotesis nol gagal ditolak. Justeru dapatan ini menunjukkan bahawa terdapat hubungan antara kecenderungan berfikir kritis dan pencapaian akademik kesusasteraan bahasa inggeris pelajar tingkatan empat. Ini bermakna apabila kecenderungan berfikir kritis meningkat pencapaian Kesusasteraan Bahasa Inggeris pelajar juga akan meningkat.

Jadual 4: Hubungan antara kecenderungan berfikir kritis dan pencapaian Kesusasteraan Bahasa Inggeris

\begin{tabular}{lccc}
\hline & Pencapaian & $\begin{array}{c}\text { Kecenderungan Berfikir } \\
\text { Kritis }\end{array}$ \\
\hline Pencapaian & Pearson Correlation & 1 & $.200^{* *}$ \\
& Sig. (2-tailed) & & .000 \\
Kecenderungan & $\mathrm{N}$ & 310 & 310 \\
Berfikir Kritis & Pearson Correlation & $.200^{* *}$ & 1 \\
& Sig. (2-tailed) & .000 & \\
& $\mathrm{~N}$ & 310 & 310 \\
\hline
\end{tabular}

**. Correlation is significant at the 0.01 level (2-tailed).

\section{Perbincangan Kajian}

Kajian ini bertujuan mengenalpasti hubungan antara kecenderungan berfikir kritis dan pencapaian Kesusasteraan Bahasa Inggeris pelajar tingkatan empat. Di samping itu, hasil penemuan kajian ini dapat menyumbang manfaat dalam melahirkan guru yang mempunyai pengetahuan terhadap kecenderungan berfikir kritis. Para guru diberikan pendedahan yang lebih sesuai seperti penggunaan alat kemahiran berfikir kritis dalam menghasilkan pembelajaran yang efektif terhadap kecenderungan berfikir kritis. Selain itu, pihak Kementerian Pendidikan Malaysia (KPM) juga boleh merancang aktiviti-aktiviti yang 
menerapkan kemahiran berfikir kritis di kalangan guru supaya guru boleh mempraktikan kemahiran ini di kalangan pelajar.

Berdasarkan kajian yang dilakukan, hasil dapatan menunjukkan tahap kecenderungan berfikir kritis analitikal berada di tahap yang tinggi. Ini kerana, pelajar telah menjelaskan bahawa guru telah menggunakan alat kemahiran berfikir kritis yang sesuai dalam mengajar mata pelajaran Kesusasteraan Bahasa Inggeris dengan melatih pelajar supaya menyelesaikan masalah yang kompleks dengan teratur. Ini selari dengan dapatan kajian lepas oleh Dewi Iryani, Wahab \& Muhlis (2018) yang menyatakan bahawa tahap analitikal berada di tahap yang tinggi berbanding aspek lain kerana guru telah menggunakan model dan alat kemahiran berfikir kritis yang sesuai untuk meningkatkan aspek analitikal dalam kalangan pelajar.

Di samping itu, hasil dapatan menjelaskan bahawa aspek berfikiran terbuka berada di tahap yang tinggi. Hasil penemuan menjelaskan bahawa pelajar bersikap berfikiran terbuka dalam menyelesaikan masalah dimana pelajar menerima pendapat orang lain dan guru juga telah menerapkan soalan yang memerlukan kamahiran berfikir kritis unutk menggalakkan pelajar untuk lebih bertanya di dalam kelas. Guru juga melatih pelajar untuk mencari maklumat yang berbeza pandangan untuk menyelesaikan masalah. Hal ini menyebabkan dapatan ini selari dengan kajian lepas oleh Jayanti, Harry, Redjeki \& Sriyati (2019) yang menunjukkan bahawa pelajar semester 3 mendapat markah yang lebih tinggi dalam aspek berfikiran terbuka berbanding pelajar semester 1 . Hal ini berlaku kerana pelajar semester 3 lebih berani untuk bertanyakan soalan di dalam kelas dan mereka mempunyai banyak pengetahuan disebabkan meraka suka untuk mencuba dan menganalisis sesuatu perkara yang baharu dalam menyelesaikan masalah.

Pengunaan internet dan multimedia membantu pelajar dalam meningkatkan aspek mencari kebenaran dalam mata pelajaran tersebut. Ini kerana, dalam menyelesaikan masalah yang berunsurkan kemahiran berfikir kritis guru menggalakkan pelajar untuk menggunakan internet atau teknologi lain bagi membantu pelajar untuk mencari fakta yang menyokong pandangan mereka. Hal ini menyebabkan dapatan aspek mencari kebenaran berada pada tahap yang tinggi dalam kajian ini. Ini selari oleh kajian lepas Jung \& Ju (2020) yang menjelaskan aspek mencari kebenaran mendapat skor min yang paling tinggi kerana pelajar menggunakan aspek mencari kebenaran dalam penggunaan komputer untuk menyelesaikan tugasan dan masalah dengan lebih baik.

Selain itu, kajian ini mendapati bahawa aspek sistematik berada di tahap tinggi. Aspek sistematik berkait rapat dengan cara seseorang individu menyelesaikan masalah dengan teratur. Melalui aspek sistematik, pelajar bersetuju bahawa dalam menyelesaikan soalan Kesusasteraan Bahasa Inggeris pelajar perlu mengetahui susunan idea yang perlu dikupas dalam soalan novel Kesusasteraan Bahasa Inggeris. Oleh hal yang demikian, aspek sistematik mengajar pelajar untuk menghasilkan idea yang teratur untuk mengatasi soalan yang memerlukan kemahiran berfikir kritis dalam mata pelajaran Kesusasteraan Bahasa Inggeris. Ia sejajar dengan kajian lepas oleh Hussen et.al (2019) yang menemui bahawa aspek sistematik mendapat skor min tertinggi dalam mata pelajaran Matematik. Kajian ini menerangkan bagaimana pelajar menggunakan aspek sistematik dengan menemukan formula dalam sesuatu kes dan mereka dapat memberi bukti dalam menyelesaikan masalah berikut.

Selain daripada itu, hasil kajian menunjukkan bahawa aspek keyakinan diri pelajar terhadap mata pelajaran Kesusasteraan Bahasa Inggeris adalah pada tahap yang tinggi. Ini menggambarkan keyakinan pelajar dalam menyelesaikan soalan yang berunsurkan kemahiran berfikir kritis. Hal ini demikian kerana guru memperbanyakkan soalan esei di dalam mata pelajaran Kesusasteraan Bahasa Inggeris. Menurut pelajar, soalan esei seperti ini mampu untuk melahirkan keyakinan diri dalam memberikan pandangan yang berbeza. Dapatan kajian ini menyokong dapatan kajian Ali dan Mohammad Javad (2020) yang menjelaskan bahawa aspek yang dipraktikan oleh pelajar dalam melahirkan pemikiran yang kritis adalah aspek keyakinan diri. Melalui aspek keyakinan diri, ia dapat membantu untuk meningkatkan kemahiran berfikir kritis pelajar dan membantu kemampuan pelajar dalam menulis esei terutamanya bagi penulisan esei Inggeris.

Dapatan kajian yang seterusnya juga menjelaskan bahawa aspek ingin tahu berada di tahap sederhana. Hal ini berlaku kerana menurut pelajar meraka menyatakan bahawa mata pelajaran Kesusasteraan 
Bahasa Inggeris tidak menyumbang mereka untuk mengunakan aspek ingin tahu dalam pemikiran mereka. Ini selari dengan kajian lepas oleh Emiliannur, Hamidah, Zainul dan Wulan (2017) yang mendapati bahawa skor min aspek ingin tahu berada di tahap yang sederhana di ujian pre-test dan posttest. Ini kerana, aspek ingin tahu tidak begitu menonjol dalam mata pelajaran Fizik.

Tahap kecenderungan berfikir kritis untuk aspek kematangan juga mempunyai skor min yang sederhana. Pandangan yang diberikan oleh orang lain mampu meningkatkan kematangan berfikir pelajar kerana cara terbaik untuk melakukan penilaian terhadap sesuatu masalah adalah dengan mendengar pandangan orang lain. Ini bermaksud pelajar tidak mempunyai kematangan dalam membuat penilian terhadap pandangan orang lain. Para guru juga tidak menerapkan amalan yang baik dalam membuat keputusan di kalangn pelajar. Dapatan ini selaras dengan kajian lepas oleh Shamala (2011) yang menerangkan bahawa aspek kematangan di kalangan pelajar mendapat skor min yang sederhana kerana pelajar dikatakan kurang bijaksana dalam membuat penilaian apabila berhadapan dengan masalah.

Tambahan pula, dapatan kajian juga menjelaskan bahawa tidak terdapat perbezaan yang signifikan kecenderungan berfikir kritis antara pelajar lelaki dan pelajar perempuan tingakatan empat. Hal ini berlaku kerana guru menggunakan alat kemahiran berfikir kritis yang sama pada pelajar lelaki dan perempuan. Oleh hal yang demikian pengetahuan pelajar lelaki dan perempuan dalam kecenderungan berfikir kritis juga hampir sama. Selain itu, pelajar berpendapat bahawa mata pelajaran Kesusasteraan Bahasa Inggeris tidak mempengaruhi pelajar lelaki dan perempuan untuk mempunyai pengetahuan yang berbeza dalam mata pelajaran ini. Dapatan kajian ini selari dengan kajian lepas Selma (2019) yang menyatakan bahawa tidak terdapat perbezaan yang signifikan antara pelajar lelaki dan perempuan terhadap kecenderungan berfikir kritis. Ini kerana, pengkaji menjelaskan bahawa dalam mata pelajaran Pendidikan Seni Visual pelajar lelaki dan pelajar perempuan mempunyai pengetahuan yang sama terhadap kecenderungan berfikir kritis.

Secara kesulurhannya, hasil dapatan kajian menjelaskan bahawa terdapat hubungan lemah antara tahap kecenderungan berfikir kritis dan pencapaian akademik pelajar tingkatan empat dalam Kesusasteraan Bahasa Inggeris di sekolah menengah Daerah Kepala Batas, Pulau Pinang. Hal ini berlaku disebabkan pelajar tidak didedahkan dengan persekitaran pembelajaran yang memerlukan kemahiran berfikir. Persikitaran yang mewujudkan pemikiran kritis mampu menggalakkan pelajar untuk bergiat aktif dalam aktiviti yang memerlukan kecenderungan berfikir kritis. Ini sejajar dengan kajian oleh Norazlinda dan Abdullah (2017) yang menjelaskan bahawa hubungan kecenderungan berfikir kritis dan pencapaian pelajar berada di tahap sederhana kerana pelajar tidak terdorong untuk mempraktikkan pemikiran kritis dan persekitaran pembelajaran juga tidak menggalakkan pelajar untuk berfikir secara kritis.

Selain itu, dapatan kajian ini juga selari dengan kajian lepas oleh Yukselir (2020) yang juga mendapati hubungan kecenderungan berfikir kritis dan pencapaian akademik pelajar tidak berkorelasi secara positif dimana pengkaji mengatakan bahawa kecenderungan berfikir kritis tidak banyak mempengaruhi pelajar dalam meningkatkan pencapaian akademik pelajar. Walau bagaimanapun, penemuan ini bertentangan dengan kajian lepas oleh Nurul, Sharifah, Halim dan Norulhuda (2018) yang mendapati bahawa terdapat hubungan yang kuat di antara kecenderungan berfikir kritis dengan pencapaian pelajar iaitu pada tahap 0.05. Hal ini kerana pelajar telah memperoleh kaedah penyampaian yang sesuai dalam pembelajaran bagi melahirkan pelajar yang mempunyai kecenderungan berfikir kritis.

Walaupun kajian ini menunjukkan keputusan yang baik melalui hasil dapatan kajian, namun terdapat beberapa limitasi kajian yang perlu dilihat. Pertama, responden kajian hanya terhad kepada pelajar sekolah menengah daerah Kepala Batas, Pulau Pinang. Pada dasarnya, kajian ini hanya dijalankan di 10 sekolah menengah daerah Kepala Batas, Pulau Pinang. Oleh itu, disarankan agar kajian selanjutnya dilanjutkan dengan melibatkan daerah yang lain di Pulau Pinang seperti Tasek Gelugor dan Bagan. Kedua, kajian akan datang juga boleh memfokuskan mata pelajaran yang berunsurkan kemahiran berfikir aras tinggi seperti mata pelajaran Fizik, Matematik dan Bahasa Melayu. Jika mata pelajaran seperti ini diberi penekanan kepada pengkaji akan datang ia mambantu untuk memperoleh penemuan dengan lebih banyak dan terperinci. Ketiga, kurangnya pendedahan kepada guru tentang penggunaan alat kemahiran berfikir dalam melahirkan pelajar yang mempunyai kemahiran berfikir kritis. Apabila guru diberi pendedahan yang lebih terperinci berkaitan alat kemahiran berfikir, ini membantu guru untuk 
menyediakan soalan-soalan yang berunsurkan kemahiran berfikir kritis dan menyediakan akativiti yang mampu melahirkan pelajar yang berfikir kritis.

\section{Kesimpulan}

Kajian ini jelas menunjukkan bahawa tahap kecenderungan berfikir kritis di kalangan pelajar tingkatan empat di sekolah menengah Daerah Kepala Batas, Pulau Pinang adalah tinggi. Ini menunjukkan bahawa semua pelajar di sekolah-sekolah yang dikaji ini bersetuju bahawa aspek kecenderungan berfikir kritis memainkan peranan yang penting dalam meningkatkan tahap pencapaian mereka dalam matapelajaran Kesusasteraan Bahasa Inggeris. Selain itu, dapatan kajian juga membuktikan bahawa tidak terdapat perbezaan pelajar lelaki dan perempuan tingkatan empat di sekolah menengah Daerah Kepala Batas, Pulau Pinang dalam kecenderungan berfikir kritis. Ini menunjukkan bahawa kebanyakan pelajar di sekolah-sekolah yang dikaji ini mempunyai pengetahuan yang sama dalam kecenderungan berfikir kritis. Ini mungkin terjadi disebabkan lokasi sekolah yang dikaji dan suasana pembelajaran yang telah diwujudkan oleh guru adalah sama.

Seterusnya, ia juga dapat disimpulkan bahawa terdapat hubungan yang signifikan antara kecenderungan berfikir krits dan pencapaian pelajar dalam matapelajaran Kesusasteraan Bahasa Inggeris di sekolah menengah Daerah Kepala Batas, Pulau Pinang. Walau bagaimana sekalipun, dapatan hubungan kajian ini menunjukkan hubungan yang lemah namun tahap kecenderungan berfikir kritis masih memainkan peranan penting dalam meningkatkan pencapaian akademik pelajar dalam Kesusasteraan Bahasa Inggeris. Ini menjelaskan bahawa dalam sistem pendidikan, aspek kecenderungan berfikir kritis perlu dititikberatkan kerana ia dapat meningkatkan pencapaian akademik pelajar.

Kajian ini terhad kepada beberapa limitasi. Oleh itu, pengkaji mencadangkan beberapa cadangan kajian lanjutan berkenaan kecenderungan berfikir kritis dan pencapaian pelajar dalam matapelajaran Kesusasteraan Bahasa Inggeris. Pada dasarnya, kajian ini mengenai kecenderungan berfikir kritis dan pencapaian akademik Kesusasteraan Bahasa Inggeris hanya dijalankan di 10 sekolah Daerah Kepala Batas, Pulau Pinang. Oleh itu, disarankan agar kajian selanjutnya dilanjutkan dengan melibatkan daerah lain di Pulau Pinang seperti Tasek Gelugor dan Bagan. Kajian lanjutan juga boleh diperluaskan ke negeri lain di Malaysia. Penemuan kajian lanjutan mengenai kajian ini diharapkan dapat meningkatkan kecenderungan berfikir kritis terhadap pencapaian akademik Kesusasteraan Bahasa Inggeris pelajar. Bagi pemilihan saiz sampel dicadangkan kajian lanjutan boleh menumpukan perhatian kepada responden yang berbeza seperti pelajar di sekolah rendah, sekolah berasrama penuh, sekolah Maktab Rendah Sains Mara (MRSM), sekolah rendah swasta dan sekolah menengah swasta. Melalui kajian lanjutan, ia dapat memberikan perbandingan yang lebih komprehensif dan lebih luas dalam hasil penemuan.

Selain itu, kajian lanjutan juga boleh mengguunakan matapelajaran yang berbeza dalam menentukan pencapaian pelajar. Pengkaji lanjutan disarankan agar mereka dapat memilih mata pelajaran yang berunsurkan kemahiran berfikir aras tinggi yang ditekankan di sekolah agar lebih banyak penemuan yang dapat diperoleh dengan terperinci dibandingkan dengan kajian ini. Seterusnya, pendedahan yang lebih terperinci berkaitan alat kemahiran berfikir harus dipraktikan di kalangan guru. Hal ini dapat membantu guru untuk menyediakan soalan-soalan yang berunsurkan kemahiran berfikir kritis dan menyediakan aktiviti yang mampu melahirkan pelajar yang berfikir kritis. Bagi kaedah pengumpulan data pula, kajian lanjutan dapat dilaksanakan dalam kaedah pendekatan kualitatif. Melalui kaedah ini, ia dapat meningkatkan data penemuan kerana pelajar dapat memberikan pendapat mereka sendiri mengenai hubungan antara kecenderungan berfikir kritis terhadap pencapaian akademik mereka. Ini kerana kaedah ini melibatkan komunikasi dua hala antara pengkaji masa depan dengan kumpulan sasaran. Berdasarkan penjelasan mereka, kajian lanjutan dapat memberikan penemuan yang lebih tepat dan dapat dibandingkan dengan penemuan kajian ini sekarang. Cadangan kajian lanjutan ini bertujuan untuk menambahbaik pada kajian yang akan datang. Kajian ini juga diharapkan agar memberi pengetahuan yang baru serta rujukan kepada kajian-kajian di masa hadapan. 


\section{Rujukan}

Aziz, A., \& Andin, C. (2018). Penggunaan strategi pembelajaran koperatif untuk meningkatkan tahap kemahiran berfikir aras tinggi pelajar (The use of cooperative learning strategies to improve students' higher order thinking skills). Jurnal Pendidikan Malaysia, 43(1), 1-9.

Bell, R., \& Loon, M. (2015). The impact of critical thinking disposition on learning using business simulations. International Journal of Management Education, 13(2), 1-22.

Creswell, J. W. (2005). Educational research: Planning, conducting, and evaluating quantitative and qualitative research. Upper Saddle River, NJ: Pearson Education.

Darby, N. M., \& Rashid, A. M. (2017). Critical thinking disposition: the effects of infusion approach in engineering drawing. Journal of Education and Learning, 6(3), 305-311.

Diputera, A. M., Setyowati, D. L., \& Susilaningsih, E. (2018). Higher-order thinking skills of junior high school students. The Online Journal of New Horizons in Education, 8(3), 61-67.

Emiliannur, E., Hamidah, I., A Zainul, A., \& Wulan, A. R. (2017). Analisis disposisi berpikir kritis fisika siswa melalui implementasi asesmen kinerja. Paper presented at the PROSIDING SKF 2017.

Ghorbandordinejad, F., \& Nourizade, F. (2015). Examination of the relationship between critical thinking disposition and English learning achievement as mediated by emotional intelligence. The International Journal of Humanities, 22(4), 83-95.

Hussen, S., Monalisa, L., Murtikusuma, R., Safrida, L., Oktavianingtyas, E., Nurdin, E., \& Rini, A. (2020). Critical thinking dispositions in solving recreational mathematics problem: opposite corners. Paper presented at the Journal of Physics: Conference Series.

Kasmuri, S. F., Adnan, N. I. M., \& Abdullah, S. N. H. (2018). Pengetahuan pelajar aliran agama dalam menerapkan kemahiran berfikir aras tinggi (KBAT) terhadap istilah berkaitan Fiqh dan Usul Fiqh: satu kajian awal a preliminary study of the knowledge of religious school students in applying high order thinking skills (HOTS) on terms related to Fiqh and Usul Fiqh. Journal of Advanced Research in Social and Behavioural Sciences, 10(1), 50-65.

Kim, J. A., \& Kim, J. O. (2020). Influence of computer attitude on critical thinking disposition. International journal of advanced smart convergence, 9(1), 1-9.

Krejcie \& Morgan. (1970). Menguasai penyelidikan dalam pendidikan: teori, analisis \& interpretasi data. PTS professional.

Liu, L. (2016). The effect of CBLL on improving students' dispositions towards critical thinking. Paper presented at the 2016 International Conference on Management Science and Innovative Education.

MacNealy, M. S. . (1999). Strategies for empirical research in writing, Allyn and Bacon, Boston.

Mulyanthi, D. I., Jufri, A. W., \& Muhlis. (2018). Critical thinking disposition of senior high school student in central lombok regency. Journal of Research \& Method in Education, 8(3), 39-42.

Myers, J. L., Well, A., \& Lorch, R. F. (2010). Research design and statistical analysis. Routledge.

Nor, M. N. A. M., Kamarudin, N., Manaf, U. K. A., \& Puad, M. H. M. (2017). Penerapan kemahiran berfikir aras tinggi (KBAT) dalam kurikulum Reka Bentuk dan Teknologi (RBT) sekolah rendah. International Journal of Education and Training, 3(2), 1-7.

Rusdin, N. M., \& Ali, S. R. (2019). Amalan dan cabaran pelaksanaan pembelajaran abad ke-21. Paper presented at the Proceedings of the International Conference on Islamic Civilization and Technology Management.

Sahari, S., \& Mahamod, Z. (2018). Persepsi guru Bahasa Melayu sekolah rendah daerah sri aman terhadap kemahiran berfikir aras tinggi dalam pengajaran dan pembelajaran (The perception of Malay language teachers in sri aman district primary schools towards the implementation of higher order thinking skills in teaching and learning). International Journal of the Malay World and Civilisation, 6(1), 63-78.

Salleh, S. Z., \& Shaari, A. S. (2019). Pelaksanaan kemahiran berfikir, sikap pelajar dan masalah untuk mengaplikasi kemahiran berfikir dalam pengajaran pembelajaran Bahasa Melayu (Implementation of thinking skills, student attitudes and problems in application thinking skills Malay language teaching). Jurnal Pendidikan Bahasa Melayu, 9(2), 1-10.

Shida, N., Osman, S., Abdullah, A. H., \& Ismail, N. (2018). Critical thinking dispositions among polytechnic students: Why does it matter? International Journal of Engineering and Technology, 7(3.25), 357-361. 
Syahfitri, J., Firman, H., Redjeki, S., \& Sriyati, S. (2019). Profil disposisi berfikir kritis mahasiswa pendidikan Biologi di perguruan tinggi. Jurnal BIOEDUIN: Program Studi Pendidikan Biologi, 9(1), 23-29.

Taghinezhad, A., \& Riasati, M. J. (2020). The interplay of critical thinking explicit instruction, academic writing performance, critical thinking ability, and critical thinking dispositions: an experimental study. IJERI: International Journal of Educational Research Innovation, (13), 143-165.

Taskesen, S. (2019). A study on art interests and critical thinking dispositions of students in fine arts department of the faculty of education. International Journal of Educational Methodology, 5(1), 275-287.

Ülger, K. (2016). The relationship between creative thinking and critical thinking skills of students. $\mathrm{H}$. U. Journal of Education, 31(4), 695-710.

Yorganci, S. (2017). The effects of podcasting on vocational school students' critical thinking dispositions for a Mathematics course. Paper presented at the International Conference on Humanities and Educational Research.

Yükselir, C. (2020). A quantitative study of turkish EFL learners' perceptions about critical thinking dispositions. International Online Journal of Education Teaching, 7(1), 126-139. 